\title{
Duguit, ¿y después? Derecho, propiedad y relaciones sociales ${ }^{1}$
}

\section{Duguit, and after? Law, property and social relations}

\section{Duguit, e depois? Direito, propriedade e relações sociais}

\section{Duguit, et après? Droit, propriété et relations sociales}

DUGUIT (杜吉特) 然后?法律, 财产和社会关系

\section{Thomas Boccon-Gibod ${ }^{2}$ Universidad Grenoble Alpes - Francia}

Revista Derechos en Acción ISSN 2525-1678/ e-ISSN 2525-1686

Año 5/No 16 Invierno 2020 (21 junio a 20 septiembre), 212-235

DOI: https://doi.org/10.24215/25251678e421

Recibido: 01/05/2020

Aprobado: 01/08/2020

Resumen: Presentamos aquí la famosa crítica duguista de la propiedad a partir de sus fundamentos sociológicos. Volvemos así sobre las dificultades con que se topó Duguit para defender su tesis según la cual la propiedad sería una "función social»: la exigencia de solidaridad sobre la que se supone que se funda el derecho resulta ser no tanto

\footnotetext{
1 Artículo original «Duguit, et après? Droit, propriété et rapports sociaux», publicado en Revue Internationale de Droit Économique, 2014/3 t. XXVIII, pp. 285 a 300. Disponible on line desde el 19 de febrero de 2015, consultado por última vez el 8-V-2020. URL: https://www. cairn.info/revue-internationale-de-droit-economique-2014-3-page-285.htm. Traducido por Claudio E. Guiñazú, Profesor de Derecho Constitucional (UNC), miembro del Grupo de Investigación en Derechos Sociales (GIDES), CIJS-UNC.

2 Doctor en filosofía, "Maître de Conferénces" en filosofía del derecho en la Universidad Grenoble Alpes y miembro del IPHIG (Institut de Philosophie de Grenoble).
} 
un hecho objetivo como una exigencia axiológica, por lo que Duguit se encuentra ante la dificultad de definir con precisión la articulación entre los hechos y los valores, que se encuentra en la base de su proyecto de refundación del derecho. Demostramos que el interés de la acción duguista reside, sin embargo, en este intento inacabado de reinscribir la noción de propiedad privada en su marco social, lo que constituye una crítica de las relaciones de poder propias de la sociedad de mercado. La originalidad de Duguit reside entonces, aún hoy, en su intento de incorporar las instituciones públicas en la crítica eficaz de tal sociedad.

Palabras clave: Duguit - propiedad - función social - valor - instituciones

Abstract: In this paper, we present the famous Duguist critique of property based on its sociological foundations. We thus return to the difficulties encountered by Duguit in defending his thesis that property would be a "social function": the demand for solidarity on which the law is supposed to be based turns out to be not so much an objective fact as a demand axiological, for which Duguit finds himself faced with the difficulty of precisely defining the articulation between facts and values, which is at the base of his project of re-founding the law. We show that the interest of the Duguist action lies, however, in this unfinished attempt to re-inscribe the notion of private property in its social framework, which constitutes a critique of the power relations inherent to the market society. Duguit's originality lies then, even today, in his attempt to incorporate public institutions into the effective critique of such a society.

Keywords: Duguit, property, social function, value, institutions

Resumo: Apresentamos aqui a famosa crítica duguista da propriedade a partir de seus fundamentos sociológicos. Voltamos assim sobre as dificuldades encontradas por Duguit para defender sua tese de acordo com a qual a propriedade seria uma "função social": a exigência de solidariedade em que o direitoi supostamente se deve basear revela-se não tanto um facto objectivo mas uma exigência axiológica, de modo que Duguit encontra-se com a dificuldade de definir com precisão a articulação entre factos e valores, que está na base de seu projecto de refundação do direito. Demonstramos que o interesse da acção de duguista reside, no entanto, nesta tentativa inacabada de 
reinscrever a noção de propriedade privada em seu quadro social, o que constitui uma crítica das relações de poder típicas da sociedade de mercado. A originalidade de Duguit reside então, ainda hoje, em sua tentativa de incorporar as instituições públicas na crítica efectiva de tal sociedade.

Palavras-chave: Duguit, propriedade, função social, valor, instituições

Résumé: Nous présentons ici la fameuse critique duguiste de la propriété basée sur ses fondements sociologiques. On revient ainsi sur les difficultés rencontrées par Duguit pour défendre sa thèse selon laquelle la propriété serait une "fonction sociale»: I'exigence de solidarité sur laquelle le droit est censé se fonder s'avère être moins un fait objectif qu'une exigence axiologique, pour lequel Duguit se trouve confronté à la difficulté de définir précisément l'articulation entre faits et valeurs, qui est à la base de son projet de refondation du droit. Nous montrons que l'intérêt de l'action duguiste réside cependant dans cette tentative inachevée de réinscrire la notion de propriété privée dans son contexte social, qui constitue une critique des rapports de force inhérents à la société de marché. L'originalité de Duguit réside alors, encore aujourd'hui, dans sa tentative d'incorporer les institutions publiques dans la critique effective d'une telle société.

Mot-clés: Duguit, propriété, fonction sociale, valeur, institutions

摘要: 我们在此介绍基于其社会学基础的著名的Duguit（杜吉特） 财产批判. 因此, 我们回到杜吉特在捍卫他的论点时遇到的困难, 他 的论点是财产将是一种“社会功能”:法律应以其为基础的对团结的 要求实际上并不仅仅是要求的客观事实, 价值论, 为此, Duguit (杜 吉特) 面临着精确定义事实与价值之间明确表述的困难, 这是他重 新建立法律的基础. 我们表明, 但杜古行动的兴趣在于, 这一未完成 的尝试将私有财产的概念重新纳入其社会框架, 这构成了对市场社 会固有的权力关系的批评. 直到今天, 杜吉特的独创性还在于他试 图将公共机构纳入对这种社会的有效批判中

关键字: 杜吉特, 财产, 社会职能, 价值, 制度 


\section{Introducción}

Para estudiar la propiedad y sus transformaciones, se privilegiará aquí la perspectiva según la cual esta noción designa o implica una determinada relación de los hombres entre sí, antes que una determinada relación de los hombres con las cosas. En efecto, si bien en general no caben dudas que la propiedad constituye también una determinada relación social, es muy difícil hacer abstracción de la relación con las cosas para comprender esta relación social, aún cuando reconocemos que el derecho que tenemos sobre las cosas podría no ser sino la cara más visible del poder de hecho que tenemos sobre los hombres debido a este derecho sobre las cosas. Querríamos así comprender en qué condiciones es posible considerar específica y radicalmente la propiedad bajo el ángulo del problema del poder, entendido como modalidad de tal relación social. La hipótesis subyacente es que, si la relación entre los hombres determina la relación que estos hombres tienen con las cosas, interesa comprender cómo modificar lo primero si queremos lograr modificar lo segundo.

Este es precisamente el interés, querríamos demostrar, del enfoque de León Duguit, célebre teórico del servicio público, así como por haber intentado concebir directamente la propiedad como una relación social, y haciendo esto, por haber intentado eliminar las dificultades a través de un trabajo sobre el concepto de norma social. Recordando rápidamente aquí los principales aspectos de esta teoría radical y alternativa de la propiedad (1.), se tratará por lo tanto, de señalar sus límites y dificultades (2.), no tanto de descalificarla, como es el caso frecuente, sino de destacar el interés que sigue teniendo desde el punto de vista de una reflexión fundamental sobre las condiciones de una crítica al dogma clásico de la relación entre propiedad privada y libertad individual. A través de la obra de León Duguit, entendida como una defensa de la tesis de las mediaciones colectivas de la apropiación individual, se tratará en suma de esclarecer la relación necesaria -cuya elaboración concreta corresponde 
emprender- entre la crítica de la propiedad privada y una teoría de las instituciones públicas.

\section{La propiedad función social: los fundamentos de una conceptualización original de la propiedad}

\subsection{Un positivismo sociológico}

León Duguit (1859-1928) es uno de los publicistas franceses de inicios del siglo $\mathrm{XX}$ cuyos trabajos permitieron establecer los fundamentos doctrinarios del derecho administrativo, un derecho nacido históricamente, a fines del siglo XIX, del simple hecho del desarrollo del contencioso así como del activismo de su jurisdicción suprema, el Consejo de Estado. En derecho público, su nombre permaneció asociado a su defensa del concepto de servicio público, y en derecho privado, a sus ataques a la noción de propiedad; pero se trata en realidad de dos aspectos indisociables de su pensamiento. De suerte que, para poder comprender su concepción de la propiedad, es necesario pasar por sus investigaciones sobre los fundamentos generales del derecho, más allá de la distinción derecho público-derecho privado, y por tanto en una dirección más allá de la distinción entre Estado y sociedad.

En efecto, el modo en que intenta sentar las bases del derecho público puede ser calificado a la vez de positivista y sociológico $^{3}$. Retomando conceptos esenciales de la ciencia social de su contemporáneo el sociólogo Émile Durkheim, él persigue, sobre el plano epistemológico, despejar el derecho de todo fundamento metafísico y proclama que aquél debe fundarse en la estructura misma de la sociedad, una estructura concebida como objetiva, independientemente de las representaciones subjetivas que de ella tienen los individuos. Pero esta posición positivista,

\footnotetext{
3 Para una comparación entre Duguit y Kelsen, ver C.M. Herrera, «Duguit et Kelsen: la théorie juridique, de l'épistémologie au politique», en 0 . Beaud et P. Wachsmann (dir.), La Science juridique française et la science juridique allemande de 1870 à 1918, Strasbourg, Presses universitaires de Strasbourg, 1997, pp. 325-345.
} 
antimetafísica, tiene inmediatamente también implicaciones sobre el plano axiológico (o político) ya que va en contra del dogma liberal de la libertad como característica puramente individual.

Estrictamente hablando, su oponente es por tanto menos la propiedad individual que, ante todo, el atomismo individualista de las teorías liberales modernas de las que constituye su justificación fundamental. Al hacerlo, Duguit busca pues, no sólo elaborar una concepción racional y científica del derecho, sino igualmente socavar los fundamentos de legitimidad de los gobiernos modernos, reemplazando, en el origen del fundamento de las decisiones públicas, la voluntad individual por la "solidaridad social". Su tesis es que la objetividad de la interdependencia social se manifiesta en esencia en la regla de derecho, una regla objetiva que, por esta razón, no puede ser objeto más que de una pura y simple "constatación" por los gobernantes encargados de ponerla en práctica.

El objeto fundamental de la teoría duguista es pues el conjunto de las relaciones de poder interindividuales. Profundamente realista, Duguit considera el ideal de igualdad como una quimera y ratifica el hecho de la desigualdad social de las fuerzas, lo que lo conduce entre otras cosas, y especialmente, a criticar el mito de la soberanía popular y a defender, contra el sufragio universal, el procedimiento de "voto plural", que daría más peso a cada uno según su valor o su dignidad social'. Simplemente, el poder que algunos ejercen sobre otros debe, según él, encontrar su fundamento y su finalidad en la interdependencia de todos $^{6}$. Es a partir de esta teoría del poder fundada sobre

4 L. Duguit, L'État, le droit objectif et la loi positive, Paris, A. Fontemoing, 1901, p. 422: "La legislación en fin es el acto por el cual los gobernantes constatan una regla de derecho objetiva».

5 L. Duguit, Traité de droit constitutionnel, t. II, $2^{\text {a }}$ ed., Paris, de Boccard, 1921, §§ 36-38, p. 451 ss. Repárese que esta misma posición había sido defendida por un liberal moderado como John Stuart Mill: ver J.S. Mill, Considérations sur le gouvernement représentatif, Paris, Gallimard, 2009, pp. 157-165.

6 Es también la razón por la cual la operación electoral, siendo menos un derecho individual que una función social, debería según él ser obligatoria. Ver L. Duguit, L'État, les gouvernants et les agents, Paris, A. Fontemoing, 1903, p. 123: «El votante tiene un deber objetivo porque 
la norma de la solidaridad social que él desarrolla un análisis de las categorías fundamentales de su ejercicio.

\section{2. ¿Transformación del derecho y fin de la propiedad?}

Desde entonces, en Las Transformaciones del derecho privado (1911) y Las Transformaciones del derecho público (1913), Duguit ataca alternativamente los dos conceptos centrales de la modernidad política que son, según él, la propiedad privada y la soberanía 7 . En Las Transformaciones del derecho privado Duguit ataca la propiedad privada como vertiente materialista del individualismo, demostrando que es la evolución misma del derecho la que indica que es necesario refundarla. El centro de su reflexión reside en la idea que la propiedad no consiste en un derecho individual, sino dentro de las necesidades colectivas. No se trata de una apología del colectivismo: Duguit entiende simplemente revelar la dimensión intrínsecamente colectiva de la propiedad, la cual no es, según él, un derecho individual "inviolable y sagrado" (en los términos de la Declaración de 1789), sino al contrario una "función social" -como el derecho al voto- tal como lo había analizado algunos años antes. Este funcionalismo parece denotar un holismo aún más radical que el de Durkheim, señalado a veces como el padre del funcionalismo en sociología, pero que sin embargo no apoyaba su defensa de una regulación centralizada de lo social, hasta el punto de recalificar los derechos individuales como funciones objetivas, socialmente determinadas ${ }^{8}$. Dicho esto, en definitiva, para el profesor de Bordeaux se trata menos de negar la propiedad que de encontrarle nuevos fundamentos, matiz sin duda decisivo como se verá.

\footnotetext{
está amarrado, como todo hombre, en los lazos de la solidaridad social. Esta obligación es incluso anterior a la ley positiva, que no es imperativa sino porque se la constata y se la sanciona».

7 L. Duguit, Les Transformations du droit privé depuis le Code Napoléon, Paris, La Mémoire du droit, 1999 [1911]; Les Transformations du droit public, Paris, A. Colin, 1925 [1913].

8 É. Durkheim, De la division du travail social, Paris, PUF, 2007 [1893].
} 
En un nuevo ejemplo de la superación necesaria de la separación entre derecho privado y derecho público, Duguit desarrolla esta crítica en Las Transformaciones del derecho público, tomando esencialmente por objeto la noción de soberanía. Él remonta la genealogía de esta última hasta la omnipotencia del padre de familia romano sobre su hogar, el dominium, el que habría dado nacimiento, por extensión, al imperium político, es decir a una forma de omnipotencia del monarca sobre el conjunto de sus conciudadanos que habría de desarrollarse nuevamente, muchos siglos más tarde, bajo la forma de la monarquía absoluta francesa. De suerte que para Duguit la soberanía está anclada en última instancia en el derecho de propiedad: son las dos caras de la creencia en la independencia del individuo frente a los otros, tipificada en el mito moderno de Robinson? Desde este punto de vista, la soberanía no puede por lo tanto designar otra cosa que la idea, escandalosa e injustificable, de una voluntad que no estaría ligada por nada más que ella misma, que estaría pues en ella misma su propio origen, y no tendría frente a otras voluntades más que derechos y ningún deber $^{10}$. Y porque ella no reposa más que sobre un fantasma, la teoría política que quería conciliar libertad individual y soberanía aparece entonces como totalmente contradictoria. La soberanía es por lo tanto la expresión, no material sino propiamente institucional del individualismo, que una vez más sólo puede ser una justificación vacía de una relación de fuerzas. A contrario, el descubrimiento de la interdependencia social opera

9 «Robinson en su isla no tiene derechos», se gritará, en lo que podría parecer un eco de las famosas críticas de Marx sobre las «robinsonadas» de la economía política moderna. Ver L. Duguit, Souveraineté et liberté, Paris, Félix Alcan, 1922, p. 138. Para un retorno reciente sobre esta figura de Robinson en el discurso antropológico moderno, ver R. Chappé et P. Crétois (dir.), L'Homme présupposé, Aix-en-Provence, Presses universitaires de Provence, 2014, 1re partie: "Le présupposé anthropologique de la robinsonnade».

10 L. Duguit, Souveraineté et liberté, op. cit., p. 83: "La soberanía es una voluntad, pero una voluntad que tiene este carácter propio, y propio de ella sola, de no determinarse más que por ella misma, una voluntad que tiene la competencia de su competencia, que es en consecuencia independiente de toda otra voluntad, una voluntad que tiene derechos pero no deberes, una voluntad que interviene siempre como voluntad dominante». 
aquí todavía como un indicador del concepto más amplio de servicio como verdadero criterio de justificación del ejercicio del poder. El Estado no es una persona moral autónoma e independiente, sino simplemente una "fuerza regulada y limitada por el derecho”. Por tal razón, para reemplazar la teoría clásica de la soberanía como fundamento del derecho público, Duguit propone la noción de servicio público, que se había utilizado durante un tiempo para definir el ámbito de aplicación del derecho administrativo ${ }^{11}$.

Como vemos, este republicanismo, por muy radical que se presente, no es ni un socialismo ni un igualitarismo, Duguit no pretende en modo alguno negar el hecho infranqueable de la desigualdad social, que es la fuente de la jerarquía material, o de poder, entre la minoría gobernante y la mayoría gobernada $^{12}$. Apuntar a la interdependencia social no es, por lo tanto, buscar la igualación de las condiciones, sino simplemente fundar las obligaciones jurídicas de los individuos particulares en la profunda solidaridad entre estos mismos individuos.

En particular, no se trata en absoluto de sustituir la propiedad privada individual por una propiedad colectiva, ni tampoco por la propiedad pública. Así, en el caso de Duguit, el patrimonio público ingresa en la teoría del Estado de Servicio Público de manera bastante secundaria, bajo la forma de un recurso destinado a reparar un daño causado a un particular, mediante una acción por exceso de poder formulada por este particular contra la administración.

Es oportuno recordar que no fue ni Duguit, ni tampoco la Escuela llamada del Servicio público, que se identificaba con este último, quienes proporcionaron los instrumentos conceptuales de las primeras olas de nacionalizaciones, en

\footnotetext{
11 Voir J. Rivero, "Maurice Hauriou et I'avènement de la notion de service public", en L'Évolution du droit public. Études offertes à Achille Mestre, Paris, Sirey, 1956.

12 Ver, para más precisiones sobre este punto, J.-M. Blanquer et M. Milet, «Les idées politiques de Léon Duguit», en F. Melleray (dir.), Autour de Léon Duguit, Bruxelles, Bruylant, 2011.
} 
tiempos del Frente popular y de la Liberación, respectivamente (1936 y 1945) ${ }^{13}$. Estas últimas se efectuaron, de hecho, de manera ampliamente pragmática, por fuera de todo marco teórico e incluso ideológico realmente estructurado, así lo indica por ejemplo la reticencia inicial del Partido comunista francés al respecto ${ }^{14}$. La justificación que se puede encontrar en el preámbulo de la Constitución de 1946, que sigue siendo famosa al respecto, parece por su parte tan ambiciosa como vaga. Cuando, en su artículo 9, dice: «Todo bien, toda empresa, cuya explotación posea o adquiera los caracteres de un servicio público nacional o de un monopolio de hecho, debe pasar a ser propiedad de la colectividad", son así puestos sobre un mismo plano una característica teórica, el servicio público, y una constatación puramente empírica, la situación monopólica, lo que es en sí totalmente ajeno al pensamiento duguista. De igual modo, si los trabajos de la Escuela del Servicio público se concentraron en las modalidades de funcionamiento orgánicas de la acción pública, la cuestión de la apropiación colectiva le ha resultado ajena.

De hecho, y para recordar al propio Duguit, la propiedad pública, de manera general, no debe ser concebida sobre la base de la personalidad del Estado (la que constituye un principio eminentemente subjetivo), sino sobre aquélla (objetiva) de la afectación de los bienes. Así, como lo destaca un lector reciente «el régimen de los bienes deriva de una verdadera escala de dominialidad que indica el vínculo que estos bienes mantienen con el propósito del patrimonio que los contiene» ${ }^{15}$. Dicho de

13 Sobre la distinción, ver la oposición entre las tesis duguistas y la Escuela del Servicio público, reagrupada alrededor de Gastón Jèze, ver 0 . Beaud, «Duguit, l'État et la reconstruction du droit constitutionnel français», en F. Melleray (dir.), Autour de Léon Duguit, op. cit., pp. 29-55.

14 Para un análisis reciente de la historia de las nacionalizaciones, ver T. Perroud, La Fonction contentieuse des autorités de régulation en France et au Royaume-Uni, tesis para el doctorado en derecho público, Université Paris I Panthéon-Sorbonne, 2011, t. I, p. 100.

15 M. Xifaras, "Le Code hors du Code. Le cas de la "transposition" de la propriété au droit administratif», Droits, 2006, n 42, p. 67. Este autor llega incluso a sostener la idea, 
otro modo, el marco de referencia sigue siendo en última instancia la solidaridad social, considerada simplemente bajo la forma de funciones, o aún de objetivos, de finalidades de las diversas acciones o fenómenos sociales.

\section{Tensiones de la teoría e interpretaciones posibles}

\subsection{La primacía de la conciencia individual: un cuestionamiento del sociologismo}

Sin embargo, pese a la impresionante coherencia de esta construcción, la articulación entre el hecho y la norma sobre la que está fundada sigue siendo nada menos que problemática. ¿Cuáles son exactamente las funciones sociales? ¿Sobre todo, quién las determina, y cómo? Duguit deja deliberadamente sin respuesta estas preguntas, no obstante decisivas: él se conforma con inferir los principios y parece dejar estas cuestiones a la Historia, es decir, en suma, a nadie ${ }^{16}$. Y pese a ello, parece poco a poco encaminado a modificar su teoría inicial de la constatación objetiva de la regla de derecho para dar lugar a factores de orden a la vez psicológico y moral. Más que por las relaciones económicas objetivas, afirma unos años después de Las Transformaciones del derecho privado, la regla de derecho se reconoce en efecto por la emoción que su violación despierta en la opinión pública, por tanto, en las reacciones subjetivas a aquélla. La sociedad se vuelve entonces más una cámara de resonancia de las emociones individuales que un mecanismo de afectación de recursos y redistribución de los bienes para salvaguardar el conjunto.

De hecho, Las Transformaciones del derecho público revelaban, desde 1913, esta inflexión del pensamiento del profesor bordelés hacia un subjetivismo que se hará cada vez más

\footnotetext{
ciertamente paradójica, de que es «arriesgado» clasificar a Duguit entre los oponentes de la propiedad privada individual (ibid., note 2).

16 «Hay algo aquí esencialmente variable, evolutivo a primera vista», afirma sobre la cuestión de la gestión monopólica de los servicios públicos por los gobernantes; ver L. Duguit, Manuel de droit constitutionnel, 4e éd., Paris, de Boccard, 1923, p. 74.
} 
marcado, haciendo de la regla de derecho el objeto no ya de una constatación racional, sino de una creencia psicológica (si bien siempre necesaria e imperativa): "El derecho, en una palabra, es una creación psicológica de la sociedad, determinada por necesidades de orden material, intelectual y moral ${ }^{17}$ ». Duguit amplía entonces el campo de sus referencias enmarcando sus reflexiones en los caracteres universales de la justicia enunciados por Aristóteles y retomados por Tomás de Aquino.

Con esta inflexión, la referencia a la objetividad de las estructuras de solidaridad social permanece vigente, pero a partir de ahora ella misma está asentada sobre una revelación íntima en el seno de la conciencia individual: «Es el estado de conciencia [...] que es finalmente la fuente creativa del derecho ${ }^{18}$ ". En el seno de esta conciencia subjetiva, distingue así un "sentimiento de socialidad", que constituye la fuente de sanción por el grupo de las conductas desviadas (la que es necesario por lo tanto presumir unánime), y el «sentimiento de justicia», el cual es "un elemento permanente de la naturaleza humana", y que es para el individuo la "prolongación" del "sentimiento de su yo»" El positivismo jurídico-sociológico parece así deslizarse hacia una verdadera filosofía moral que no se apoyaría más que secundariamente sobre las realidades socio-económicas, pero tomaría por momentos rasgos casi místicos ${ }^{20}$. Así, la «justicia distributiva»

17 Ibid., p. 45. Ver también esta recuperación de Rousseau -autor que sin embargo él había criticado duramente por su individualismo- en Souveraineté et liberté (un texto originado en una serie de conferencias en las que Duguit pretendía efectuar un balance moral de la Primera Guerra mundial): «Lo que hace a una nación es la existencia de una conciencia común, siguiendo la expresión de J.J. Rousseau, la existencia de un yo común, y también la búsqueda del ideal común relacionado a la posesión de un determinado territorio», L. Duguit, Souveraineté et liberté, op. cit., p. 43. Duguit, en este texto, intenta así dar sentido a la idea de nación, como amor a la patria vinculado a la figura de un determinado territorio, desligándola del concepto de soberanía. De tal modo, el Rousseau que presenta parece haber sido influenciado por Ernest Renan.

18 L. Duguit, Traité de droit constitutionnel, t. II, op. cit., p. 45.

19 Ibid., pp. 49-50.

20 Esta es la interpretación más racional que parece fundada en proponer una fórmula tal como: "Esta doctrina ha encontrado numerosas objeciones. Poco me importa. Yo establezco 
aparece clásicamente definida como caracterizando las relaciones "de la parte en el todo", igualando bienes y honores de manera proporcional a los servicios y funciones prestados a la comunidad, mientras que la "justicia conmutativa", que califica los vínculos "de parte a parte», es definida por su parte como el "fundamento de la solidaridad por la división del trabajo» ${ }^{21}$.

Tal referencia, por tradicional que pueda parecer, constituye no obstante una cierta inflexión "socializante» respecto de la interpretación corriente (y compatible con el individualismo liberal) según la cual esta justicia conmutativa, también llamada "aritmética", o aun "correctiva", caracterizaría esencialmente las relaciones puramente privadas o contractuales: para Duguit es la interdependencia social la que protege de hecho. Asimismo, como vemos, la sociedad entera está aún presente en sus miembros, al menos en principio, incluso cuando tratan de parte a parte: es siempre su buen funcionamiento global lo que está aquí en juego. La referencia a santo Tomás indica pues simplemente, en suma, que Duguit, obligado a apelar a la conciencia individual, es llevado a apoyar su objetivismo sociológico en un conjunto de categorías más abstractas y más generales para evitar disolver el sentimiento de justicia en el subjetivismo perspectivista que siempre combatió. Esto confirma, si fuera necesario, el hecho de que su oponente, desde el principio, es menos el subjetivismo jurídico que el individualismo liberal, el cual, haciendo abstracción de las relaciones sociales, ve en la sola relación del individuo con las cosas el alfa y el omega de la libertad política, sin preocuparse de los efectos de la violencia de la que es portadora esta abstracción. Sin embargo, el alcance de la referencia sociológica a las funciones sociales, y la determinación de estas últimas, aún no están claros.

\footnotetext{
la regla de derecho; lo afirmo como un postulado inquebrantable», L. Duguit, Traité de droit constitutionnel, t. II, op. cit., p. 111.

21 Ibid., pp. 52-53. La referencia citada por Duguit es santo Tomás de Aquino, Somme théologique, Ila Ilae, q. 58, art. 8, et q. 59, art. 1 et 2. Ver igualmente Aristóteles, Éthique à Nicomaque, V, ch. 5-7, 1130 b 30-1132 b 20.
} 
No menos lamentable, este desplazamiento hacia la subjetividad individual tiene igualmente consecuencias sobre la concepción duguista del Estado, que tiende finalmente a resurgir como una instancia tutelar por encima de las voluntades individuales, en contradicción con la concepción de un Estado reducido, según otra fórmula famosa, a una pura "cooperación de servicios públicos organizados y controlados por los gobernantes ${ }^{22}$. No es imposible, así, que esta ambigüedad constituyera la brecha que aprovecharon después los miembros de la Escuela del Servicio público, que, concentrándose en los caracteres orgánicos de este último, contribuyeron a estatizar lo que para Duguit constituía un principio general válido tanto para el derecho privado como para el derecho público ${ }^{23}$.

Así, en definitiva, del hecho de sus inconsistencias profundas, ya sea para la propiedad como para las instituciones públicas, la gran maquinaria duguista es con frecuencia considerada como una pura y simple pantalla ideológica, cuya significación objetiva bien podría ser la legitimación del orden instituido en los comienzos de la III ${ }^{a}$ República, cuando no la elaboración de una reacción antiparlamentaria alimentada por la búsqueda de reconocimiento simbólico de algunos notables provinciales ${ }^{24}$. Empero, parece necesario destacar que la intuición duguista de considerar las relaciones de propiedad desde el ángulo de las relaciones de poder, sometiendo estas relaciones de poder a una norma común, a la vez social y moral, sigue siendo no

22 L. Duguit, Traité de droit constitutionnel, t. II, op. cit., pp. 71-72. Es una de las principales críticas que formula al respecto É. Pisier en su estudio Le Service public dans la théorie de l'État de Léon Duguit, Paris, LGDJ, 1972, p. 289.

23 Como lamenta Olivier Beaud («Duguit, l'État et la reconstruction du droit constitutionnel français», loc. cit.), sin quizás informar suficientemente las derivaciones que él deplora de las dificultades del propio Duguit; ver sin embargo los matices aportados desde entonces en su juicio sobre Jèze, ibid., «L'œuvre de Gaston Jèze signifie-t-elle un repli de la doctrine publiciste française sur la technique juridique?», Jus politicum. Revue de droit politique décembre 2013, $n^{0}$ 11, http://www.juspoliticum.com/L-œuvre-de-Gaston-Jeze-signifie-t.html (consultado el 29 de octubre de 2014).

24 Ver sobre este punto, G. Sacriste, La République des constitutionnalistes. Professeurs de droit et légitimation de l'État en France (1870-1914), Paris, Presses de Sciences Po, 2011. 
obstante portadora de una radicalidad que, sin duda, no es sólo teórica.

\subsection{Más allá de la propiedad: la crítica del valor de mercado}

De hecho, la idea de que la apropiación individual debe ser objeto de una cualificación social, ciertamente ha parecido muy radical a sus contemporáneos, y el funcionalismo de Duguit puede en efecto parecer desmesurado en la medida en que parece subordinar totalmente la libertad individual a una pura determinación social. No obstante, en Duguit este holismo no conduce ni a una teoría del gobierno de los sociólogos expertos (como parece ser a veces el caso de Durkheim), ni tampoco a una teoría del gobierno de los jueces; más ciertamente sin duda -y a lo sumo- a una teoría del magisterio de los profesores de derecho, que se ocupa de denunciar de ahora en adelante la sociología crítica de este último ${ }^{25}$.

No obstante, si se presta mayor atención a Duguit, se podrá decir entonces que él, en el momento en que parece hundirse en la incoherencia de la contradicción entre los fundamentos subjetivo y objetivo de la regla de derecho, no es más que la víctima de su ambición por formular la exigencia de justicia, que es propiamente moral, sobre la base de relaciones de poder objetivadas y racionalizadas. Él demuestra así de hecho que, contrariamente a los propios dogmas racionalistas, en particular, a la economía política moderna, que desde el siglo XIX se impuso como la principal ciencia de gobierno de las sociedades occidentales, la realidad social no puede ser aprehendida únicamente de manera objetiva como en las ciencias naturales, sino que es -primero y ante todo- objeto de juicios de valor $^{26}$. Así pues, las ciencias sociales no están exentas de tensiones resultantes de debates morales y políticos, y por lo

25 Ibid.

26 Para una revisión crítica de la historia de la separación entre ciencias naturales y ciencias humanas, ver, B. Latour, Nous n'avons jamais été modernes, Paris, La Découverte, 2005 [1997]. 
tanto no susceptibles de ser resueltas por una simple reflexión epistemológica $^{27}$. Pero sobre todo, él también demuestra de hecho que estos juicios morales deben formularse, a partir de ahora, en el lenguaje de las ciencias sociales, generando entonces cierta subversión de las categorías fundamentales de estas últimas.

Podríamos en este caso ampliar la intuición de Duguit sobre la dimensión estrictamente social de la propiedad a la manera de ciertos economistas heterodoxos contemporáneos que, en lugar de criticar los fundamentos jurídicos de la propiedad, se interesan por el modo en que es movilizada en los intercambios mercantiles. Como sabemos, a la luz de Durkheim entre otros, aquéllos consideran que los mercados no son lugares de intercambios naturales y axiológicamente neutros entre bienes y servicios que son intrínsecamente portadores de valor para sus diferentes propietarios, sino precisamente como instancias de valoración de estas mismas mercancías ${ }^{28}$.

El corazón del problema, para un economista heterodoxo como André Orléan, parece ser entonces la estructuración de estas instancias sociales para la valoración de los bienes. Esto conduce a considerar el valor de un bien (el supuesto fundamento de su valor de mercado, y que justificaría su apropiación pública o privada), no como una propiedad natural del bien, sino como el producto de una relación social -o "convención»determinada en gran medida por comportamientos puramente

\footnotetext{
27 Tal afirmación presupone una serie de tesis que es imposible comenzar a discutir aquí, sobre el problema de la racionalidad de los juicios de valor. Sin llegar a sostener una forma de decisionismo maximalista que desearía que los valores no sufran ninguna forma de apreciación racional, podemos simplemente señalar que la discusión epistemológica en ciencias sociales, aunque sin duda no puede decidir directamente sobre cuestiones axiológicas, puede sin embargo arrojar luz sobre ellas, y eventualmente, por este medio, transformarlas. Nos alineamos en este punto con la opinión de Albert Hirschman que sugería que la historia de las ideas, si bien no puede zanjar directamente el debate político, puede al menos «mejorarlo». Ver A.0. Hisrschman, Les Passions et les intérêts, Paris, PUF, 2005 [1980], p. 121.

28 Ver especialmente A. Orléan, L'Empire de la valeur. Refonder l'économie, Paris, Seuil, 2011, ch. V, p. 199 ss. (para la referencia a Durkheim).
} 
miméticos ${ }^{29}$. Orléan concluye, de manera explícitamente contraria a los dogmas ultraliberales preconizados desde los años ochenta, que los mercados financieros supuestamente "autorregulados" no deberían quedar librados a sus propios medios, so pena de asistir a fenómenos aberrantes y catastróficos de especulación descontrolada ${ }^{30}$.

Sin entrar en más detalles de un problema que no es objeto inmediato del presente trabajo, podemos ver en este análisis una extensión del aspecto más objetivista de la crítica duguista de la propiedad, en la medida en que la dimensión moral está todavía situada en segundo plano, tras una reflexión esencialmente funcionalista sobre la estructuración de las interacciones individuales dentro de sociedades determinadas ${ }^{31}$. El reconocimiento de la noción de valor es aquí indiscutiblemente mucho más crítico y preciso que la vaga "constatación" de la norma social, invocada por Duguit en sus primeros estudios sobre el Estado y la ley positiva; sin embargo, la articulación entre la crítica del valor de mercado y el ideal moral de justicia se encuentra aquí disminuida en nombre de una evaluación rigurosa e imparcial -en una palabra, científica- del funcionamiento de los mercados. Tal crítica de la noción de valor tiene un aspecto inacabado, sin vínculo claro con una teoría de la organización social legítima: para decirlo de otro modo, la crítica de la economía política no encuentra aquí una teoría del Estado ni de la democracia, como era la ambición de Duguit, quien para hacer esto, lo hemos visto, llegaría hasta reivindicar de manera casi mística la pura singularidad de su apego a la regla de derecho como expresión de la solidaridad social ${ }^{32}$.

\footnotetext{
29 Ibid., ch. II. El modelo mimético utilizado por A. Orléan es el del antropólogo René Girard.

30 Ibid., tercera parte.

31 Sabemos que la Escuela de la Regulación, históricamente surgida, en parte al menos, de las estructuras gubernamentales del Estado francés, prefirió explícitamente los estudios monográficos por países o por zonas económicas a los tratados generalistas de ciencia económica, suscribiendo así una concepción de la ciencia económica relativamente libre del cientificismo y el universalismo atribuidos a la economía neoclásica estándar.

32 Uno de los límites del enfoque de Orléan, en su crítica del sustancialismo objetivo de la concepción neoclásica del valor, es que no tiene en cuenta la teoría subjetivista y
} 


\subsection{Propiedad y valor de mercado: el rol de las instituciones públicas}

Sin embargo, parece que esta intuición, según la cual la propiedad no tiene más significación que para una sociedad históricamente determinada, podría tener un alcance todavía más profundo, en la medida en que pone en tela de juicio la noción misma de bien natural apropiable, es decir de mercancía. En otras palabras, si el valor de una cosa debe ser entendido no como una propiedad intrínseca de esa cosa, sino como el resultado de un proceso social de valorización, es porque existe la posibilidad lógica de que ciertas cosas sean inapropiables en razón de la imposibilidad misma de asignarles un valor.

No se trata, en este sentido, de definir cuáles serían estas cosas que milagrosamente escaparían por naturaleza a la economía capitalista: al contrario, sabemos muy bien que nada podría escapar de ella por principio, la historia del capitalismo puede leerse como la historia de la extensión del dominio de la mercancía, hasta el propio "capital humano". Se trata, más bien, de destacar que la posibilidad misma de valorización supone, como primer correlato lógico, la categoría de lo inapreciable; y por lo tanto, del mismo modo, que la categoría de bien apropiable supone formalmente la de bien inapropiable ${ }^{33}$. Criticar la propiedad en nombre de su dimensión social remite entonces a los límites mismos de proceso social de valorización de los bienes, y a la dimensión profundamente arbitraria en sí misma de los juegos de valorización en los que nuestras vidas se encuentran comprometidas a través de nuestra participación en la economía de mercado.

perspectivista del valor de mercado, tal como ha sido desarrollada por los miembros de la Escuela de Economía Austríaca, en particular F.A. Hayek. (ver Droit, législation et liberté, Paris, PUF, 2007, ch. 10, p. 545 ss.). En efecto, el autor se ha defendido de un modo que puede juzgarse insuficientemente convincente: ver "Le néo-libéralisme entre théorie et pratique», Les Cahiers philosophiques, 2013/2, n 133, pp. 9-20.

33 Para una reflexión similar, ver J.-M. Harribey, La Richesse, la valeur et l'inestimable, Paris, Les Liens qui Libèrent, 2013. 
La concepción de una propiedad determinada únicamente por su función social -para retomar las categorías duguistas- conduce entonces, muy concretamente, al examen de los procedimientos sociales por los que un bien o un conjunto de bienes es reconocido como susceptible de ser apropiado a fin de ser intercambiado. ¿En qué condiciones sociales un bien puede ser reconocido como dotado de valor de mercado, y por lo tanto como un bien apropiable, es decir, como el fundamento para la existencia misma de un mercado?

Un acontecimiento reciente parece ofrecer una ilustración esclarecedora al respecto: la destrucción pública, al pie de la Torre Eiffel, por las autoridades francesas en febrero de 2014, de tres toneladas de marfil ilegal, incluyendo 800 kilos de objetos trabajados y 2,2 toneladas de colmillos de elefante "en bruto». Constituyó la primera operación europea, pero no fue algo sin precedentes a nivel mundial, tampoco permaneció sin consecuencias: desde entonces, el 15 de mayo de 2014, las autoridades de Hong Kong procedieron a la destrucción «record" de casi treinta toneladas de marfil.

A primera vista, tal gesto parece bastante abierto a la interpretación en el marco conceptual del liberalismo económico: en la medida en que se trata de un comercio prohibido, contraviene el marco jurídico del Estado de derecho, que un pensador como Hayek ha demostrado claramente que es una disciplina moral beneficiosa, la condición "civilizatoria", de la economía de mercado ${ }^{34}$. Recordemos en efecto que para Hayek -cuya síntesis excepcionalmente acabada entre teoría económica y teoría política no siempre parece suficientemente resaltada, al tiempo que este carácter único lo hace un oponente de talla para la reflexión crítica- el derecho y las instituciones públicas son partes interesadas del orden social legítimo, a título de condición negativa para el advenimiento de la organización espontánea de los individuos en torno a la competencia del

34 F.A. Hayek, Droit, législation et liberté, op. cit., ch. 8. 
mercado $^{35}$. No obstante, el tipo de reglas negativas que Hayek tenía en miras se refería más a la disciplina de mercado (evitar los fraudes y otros abusos como el uso de información privilegiada) que a la restricción del imperio del mercado en nombre de principios que consideran la inscripción de la acción humana en su entorno natural.

Por consiguiente, una aproximación más minuciosa, y probablemente más honesta, permite ver aquí una manifestación perfomativa del carácter social último de la noción misma de mercancía. Aunque, claramente, no se trata de una simple comunicación de un mensaje o de una información. Si tal fuera el caso, en efecto, podríamos ver aquí no más que una operación puramente utilitaria: destruyendo la reserva de marfil, las autoridades indicarían a los traficantes que no tengan expectativas del levantamiento de la suspensión que prohíbe su comercio $^{36}$. Sin embargo, bajo un punto de vista etnológico, este gesto parece tener un significado muy diferente, que estaríamos tentados de calificar de sacrificio, si no fuera muy sospechoso ver aquí una especie de vocación expiatoria hacia los elefantes masacrados, y que en todo caso tal gesto resultaría inútil si no se tomaran medidas más operativas en las fronteras y sobre el territorio para detener el tráfico internacional de marfil, de hecho actualmente en pleno auge. Aunque no es un sacrificio estrictamente hablando, este gesto tiene, sin embargo, una indudable dimensión perfomativa y simbólica: se trata en efecto de

\footnotetext{
35 Nos permitimos reenviar sobre este punto a nuestro estudio: Autorité et démocratie. L'exercice du pouvoir dans les sociétés modernes, préf. É. Balibar, Paris, Institut Varenne/ LGDJ, 2014, ch. 10, p. 424 ss.

36 Según este punto de vista, tal acción podría incluso resultar contraproducente ya que, al destruir las reservas de marfil ilegal y, por lo tanto, haciendo escasa la oferta disponible a largo plazo, contribuiríamos directamente a hacer subir el valor del recurso aún existente (elefantes silvestres), incitando así a los traficantes a intensificar la explotación de este mismo recurso. Esto sería sin duda prestarse los gobernantes a una ingenuidad culpable, lo que, por lo demás, es cosa corriente en los razonamientos propios del liberalismo económico, que tienden a interpretar el problema de la limitación del poder de los mercados esencialmente como un problema de organización de estos mismos mercados (mediante mecanismos de incentivo destinados a los productores y consumidores).
} 
negar a estos objetos la posibilidad misma de ser considerados dignos de apropiación, y esto, a pesar de las apariencias (a saber, el trabajo al que se han sometido algunas de estas defensas). De hecho, Kenia había comenzado tales destrucciones poco antes de la suspensión internacional sobre el comercio de marfil instaurada en 1989: se trataba entonces de ayudar a justificar esta suspensión, poniendo fin a la apropiación comercial de estas piezas de animales.

Es así que Nicolas Hulot, una personalidad invitada por el Presidente de la República junto al entonces Ministro de Medio Ambiente, pudo declarar en el lugar: "Decimos con este gesto que el marfil ya no tiene valor ${ }^{37}$. Tal negación puede ser calificada de perfomativa en la medida en que produce las condiciones mismas de su inteligibilidad; lo que ilustra el hecho que el valor de mercado y la propiedad son instituciones sociales, y que el valor de las cosas puede ser determinado por un trabajo propiamente simbólico (pero no sin un efecto real) en el que las instituciones públicas juegan un rol decisivo. Esta versión antropológica, antes que estrictamente sociológica, parece así constituir la interpretación más convincente y más profunda de la que sería susceptible la intuición duguista de las mediaciones sociales de la propiedad.

\section{Conclusión}

A modo de conclusión, quisiéramos intentar generalizar esta reflexión volviendo a una intuición fundamental de esta conceptualización alternativa de la propiedad, a saber, la reflexión sobre las relaciones de poder como condición previa a la reflexión sobre la relación con las cosas.

Evidentemente, la radicalidad de esta intuición le confiere un cierto poder de seducción. Sin embargo, si nos contentamos

\footnotetext{
37 Citado en Le Monde, 6 de febrero de 2014, disponible en línea: http://www.lemonde.fr/ planete/article/2014/02/06/face-a-la-flambee-du-trafic-international-la-france-detruit-sonstock-d-ivoire-illegal_4361021_3244.html (consultado el 29 de octubre de 2014).
} 
con decir que las representaciones que hacemos de la realidad son insuficientes y distorsionadas en relación con la "realidad profunda" de las relaciones sociales, en definitiva que son ideológicas, corremos el riesgo de hundirnos en una forma de confusión tanto epistémica como axiológica. Es la impresión que muchos pueden sentir respecto de pensadores como Marx, Foucault o aún Maquiavelo, que pasan por teóricos del poder y cuya interpretación no resulta siempre fácil. Para evitar este riesgo, si queremos continuar fundando su reflexión sobre las relaciones de poder y evitar así sucumbir al fetichismo de la mercancía, existe la gran tentación de reducirlas a un conjunto más o menos mecánico, denominado «relaciones sociales», o aún «interdependencia social», como intentó hacer Duguit precisamente al inicio de su carrera. Es también un vicio en el que han caído muchos comentaristas de Marx, para quienes las relaciones sociales parecen a veces reducirse a las leyes de desarrollo de las fuerzas productivas ${ }^{38}$. Entre el sistematismo objetivista, incluso cosificador, y la confusión pura y simple causada por una fascinación un tanto ingenua por las "relaciones de poder» desprovistas de toda referencia teórica o normativa, una cierta preocupación por el realismo conduce, pues, a clarificar el status y el rol de las instituciones, en particular las instituciones públicas, en la determinación de las relaciones de los hombres entre sí y con las cosas. Dicho de otro modo, para operar sobre la propiedad y transformarla, convendría no interesarse únicamente por la estructura de los bienes, ni tampoco por la de los intercambios, sino tener en cuenta también sus condiciones sociales de existencia, es decir, el juego, propiamente simbólico, que los individuos juegan en y con el conjunto de las instituciones sociales ${ }^{39}$.

\footnotetext{
38 Este es un punto sobre el que se focalizó en los últimos años el Ilamado movimiento de "crítica radical del valor». Ver M. Postone, Temps, travail et domination sociale, Paris, Mille et une nuits, 2009; A. Jappe, Les aventures de la marchandise. Pour une nouvelle critique de la valeur, Paris, Denoël, 2003, y más recientemente É. Martin, M. Ouellet (dir.), La Tyrannie de la valeur, Paris, Écosociété, 2014.

39 Nos permitimos reenviar nuevamente a nuestra obra precitada para más desarrollos sobre el concepto de institución al que se hizo referencia aquí (Autorité et démocratie, op. cit., ch. 5 et 7).
} 
Por lo tanto, es también a la realidad particular de las instituciones (el mercado, la administración, el gobierno, etc.) a la que debe orientarse el esfuerzo de definición normativa, a fin de evitar que la acción política se reduzca a un cara a cara, tan desesperante como estéril, entre la fuerza y la moral.

\section{Bibliografía}

Aristóteles (1978) Ética a Nicómano. Ed. Aguilar, Buenos Aires.

Beaud, Olivier (2011) “Duguit, l'État et la reconstruction du droit constitutionnel français “, en F. Melleray (dir.), Autour de Léon Duguit. Ed. Bruylant, Bruselas.

Blanquer Jean Michel y Milet, Maurice (2011) "Les idées politiques de Léon Duguit", en F. Melleray (dir.), Autour de Léon Duguit. Ed. Bruyant, Bruselas.

Boccon, Thomas (2014) Autorité et démocratie. L'exercice du pouvoir dans les sociétés modernes. Institut Varenne/LGDJ, París.

Chappé, Robert y Crétois, Pierre (2014) L'Homme présupposé. Presses universitaires de Provence, Aix-en-Provence.

De Aquino, Tomás (1986) Suma de Teología. Ed. Gredos, Barcelona. Duguit, León (1901) L'État, le droit objectif et la loi positive. Ed. Fontemoing, París.

- (1903) L'État, les gouvernants et les agents. Ed. Fontemoing, París.

- (1921)Traité de droit constitutionnel. Ed.de Boccard, París.

- (1922) Souveraineté et liberté. Ed Félix Alcan, París.

- (1923) Traite de droit constitutionnel. Ed. de Boccard, París.

- (1925) Les Transformations du droit public. Ed. Colin, París.

- (1999) Les Transformations du droit privé depuis le Code Napoléon. Ed. La Mémoire du droit, Paris.

Durkheim, Émile (2007) De la division du travail social. PUF, París. Harribey, Jean (2013) La Richesse, la valeur et l'inestimable. Les Liens qui Libèrent, París.

Hayek, Friedrich August (2007) Droit, législation et liberté. PUF, París.

Herrera, Carlos Miguel (1997) "Duguit et Kelsen: la théorie juridique, de l'épistémologie au politique" en La Science juridique 
française et la science juridique allemande de 1870 à 1918. Presses universitaires de Strasbourg. Strasbourg.

Hisrschman, Albert (2005) Les Passions et les intérêts. PUF, París.

Jappe, Robert (2003) Les aventures de la marchandise. Pour une nouvelle critique de la valeur. Denoël, París

Jèze, Gaston (2013) 'L'œuvre de Gaston Jèze signifie-t-elle un repli de la doctrine publiciste française sur la technique juridique? " en Jus politicum. Revue de droit politique. En línea en http:// www.juspoliticum.com/L-œuvre-de-Gaston-Jeze-signifie-t.html

Mill, John Stuart (2009) Considérations sur le gouvernement représentatif. Gallimard. París.

Latour, Bruno (2005) Nous n'avons jamais été modernes. La Découverte. París.

Orléan, André (2011) L'Empire de la valeur. Refonder l'économie. Seuil. París.

Ouellet, Martin (2014) La Tyrannie de la valeur. Écosociété. París

Perroud, Thomas (2011) La Fonction contentieuse des autorités de régulation en France et au Royaume-Uni. Université Paris I Panthéon-Sorbonne. París.

Pisier, Éugene (1972) Le Service public dans la théorie de l'État de Léon Duguit. LGDJ. París

Postone, (2009) Temps, travail et domination sociale. Mille et une nuits. París.

Rivero, Jean (1956) "Maurice Hauriou et l'avènement de la notion de service public", en L'Évolution du droit public. Études offertes à Achille Mestre. Ed. Sirey. París.

Sacriste, Guillaume (2011) La République des constitutionnalistes. Professeurs de droit et légitimation de l'État en France (18701914). Presses de Sciences Po. París

Xifaras, Mikhail (2006) «Le Code hors du Code. Le cas de la "transposition" de la propriété au droit administratif» en Droits. $\mathrm{N}^{\circ}$ 42. París. 